\title{
Sustainability-related Communication Patterns on the Websites of European Top $\mathrm{R} \& \mathrm{D}$ Spenders

\author{
Giacomo Liotta, Stoyan Tanev, Andrea Gorra, \\ and Alicja Izabela Pospieszala
}

\author{
" Sustainability communications can bring your business many benefits, and \\ help you stand out from your competitors. "'
}

Amfori

A guide to effective sustainability communications

\begin{abstract}
Many firms struggle to incorporate "sustainability" into their operations in a way that can capture economic value and deliver social and environmental benefits. This article aims to answer two questions in this regard: (i) How do companies articulate the sustainability aspects of their businesses online, and (ii) In what ways does the degree of articulation of specific sustainability aspects relate to company performance metrics, such as sales and R\&D expenditure. The research method measures the occurrences of a set of sustainability-related keywords on the websites of a sample of 387 firms that were ranked as top R\&D spenders in Europe for 2013. We processed the keyword occurrences in a simplified version of latent semantic analysis based on the application of principal component analysis to identify the specific combinations of words used by companies to communicate sustainability issues on their websites. The results show that "sustainable innovation" and "sustainable operations" based on partnerships and cooperation represent a dominant part of companies' online communication strategies. One of the findings suggests a strong relationship between the communication of sustainable innovation aspects and sales, which offers a promising message to companies looking for evidence about the potential impact of their commitment to sustainable operations and innovation.
\end{abstract}

\section{Introduction}

Sustainability concerns have become a major driver of business change (Seebode et al., 2012) and innovation (Nidumolu et al., 2009). The quest for sustainability is now transforming the competitive business landscape, which forces companies to reconsider the ways they think about products, services, processes, and business models (Nidumolu et al., 2009). The importance of making a shift from adopting traditional business models focused exclusively on process optimization and economic return, to business models that integrate sustainability concerns into a firm's strategy and business operations has been increasingly emphasized (Matos \& Silvestre, 2013; Boons et al., 2013). Sustainable business model innovation involves changing the very ways firms do business (Bocken et al., 2014). Unfortunately, there little research has been done on how exactly companies can most effectively embed sustainability issues into their businesses and revenue models (Seebode et al., 2012). There is even less research on how companies communicate the focus of their sustainability efforts as well as the potential value of these efforts for their customers and stakeholders in general.

The present article contributes to answering two specific questions: (i) How do companies articulate the sustainability aspects of their businesses on their websites?, and (ii) In what ways does the degree of articulating specific sustainability aspects relate to a company's performance metrics, such as sales and $R \& D$ expenditure? We focus on top R\&D spenders in Europe, that is, a type of company that is highly inclined to pursuing sustainable innovation, such that they consider R\&D spending not only as an engine of economic 


\section{Sustainability-related Communication Patterns on the Websites of European Top R\&D Spenders Giacomo Liotta, Stoyan Tanev, Andrea Gorra \& Alicja Izabela Pospieszala}

growth, but also as a driver of sustainable development (Fernández et al., 2018).

The article is organized as follows. The next section describes key insights gained from the literature review we conducted focusing on sustainable innovation, sustainable business models, the benefits of sustainability, and the analytical method that was applied to develop research insights. The third section describes the method used. The fourth section summarizes the results. The fifth section offers an analysis of the results, followed by the final section, which focuses on the study's main contributions and its relevance for scholars and practitioners.

\section{Key Insights from Literature}

\section{Sustainability and Innovation}

"Sustainable innovation" has been described in the literature with different terms and embedded in conversations using several related concepts. The term is used somewhat interchangeably with eco-innovation, green innovation (Boons \& Lüdeke-Freund, 2013), and sustainability-oriented innovation (Hansen et al., 2009; Klewitz \& Hansen, 2014; Neutzling et al., 2018). It is grounded in wider notions such as environmental sustainability (Boons \& Lüdeke-Freund, 2013) and sustainable development (Nidumolu et al., 2009). According to Hansen et al. (2009), integrating sustainability and innovation activities carries importance both from normative and business perspectives. The normative perspective relates to solving societal and environmental challenges and problems. It can be seen through the development of new areas of innovation such as, for example, new technologies supporting the elimination of waste. The business perspective relates to the interplay between sustainable innovation management and business opportunities. Innovation pressure comes often from regulations and policies regarding environmental and social matters. Furthermore, the challenges associated with adopting a sustainability paradigm can be a valuable source for generating new business ideas.

The quest for sustainability has therefore put a normative demand on innovation to become more environmentally and socially friendly (Hansen et al., 2009). At the same time, seeking sustainability can provide a new source of innovation and competitive advantage. By treating sustainability as a priority today, early movers can develop competencies that rivals will be hard-pressed to match (Nidumolu et al., 2009).
Sustainable innovation, however, requires organizations to rethink their businesses, reshape their value chains and use resources in innovative ways (Lampikoski et al., 2014). More specifically, Claudy, Peterson and Pagell (2016) argue that firms with an explicit sustainability orientation are more likely to find innovative solutions to ecological and social problems. Taking a sustainability orientation can result in operational efficiencies, higher quality products, greater value for customers, and in new product development success. In order to solve the trade-offs between sustainability goals and profitability aims, firms must engage in intensified learning and market knowledge development to identify and develop solutions that satisfy economic, environmental, and social objectives (Claudy et al., 2016).

\section{Sustainable Business Models and Innovation}

According to Charter \& Clark (2007), "Sustainable innovation is a process where sustainability considerations (environmental, social, financial) are integrated into company systems from idea generation to research and development (R\&D), and commercialisation. This applies to products, services and technologies, as well as new business and organisation models". Sustainable innovation thus widens the previous concept of eco-innovation, which emphasizes the need for environmental performance improvement (Carrillo-Hermosilla et al., 2010), because it also includes the social dimension and a more holistic, long-term perspective involving sustainable development (Boons et al., 2013).Impactful sustainable innovation opens new global market opportunities, fosters smart specialization of regions, and spurs longterm policy actions by governments (Boons et al., 2013). At the same time, it tends to be included at the end of the development process, making it difficult to achieve more than incremental improvements (Vandaele, Decouttere, 2013). Operations striving for sustainability need to be properly integrated into business model frameworks in order to enable the delivery of the expected benefits for all relevant stakeholders. A lack of concrete frameworks exists, however, that can help turn sustainable innovations into business model innovations. Researchers have already discussed the relationship between sustainable innovation and business models by considering the sustainability aspects of the interplay between business model components, the potential for value creation in the supply chain, and revenue models (Boons \& LüdekeFreund, 2013; Boons et al., 2013). At the same time, the question of how business models should adopt a more comprehensive view regarding sustainability has not 


\section{Sustainability-related Communication Patterns on the Websites of European Top R\&D Spenders Giacomo Liotta, Stoyan Tanev, Andrea Gorra \& Alicja Izabela Pospieszala}

been systematically addressed in the literature (Bocken et al., 2014).

\section{The Benefits of Sustainability}

Multiple benefits of sustainability have already been discussed in the literature. Some of the examples are summarized as follows:

- Eco-design and eco-efficiency improvements have helped in reducing energy, resource intensity, emissions, and waste per unit of production (Bocken et al., 2014).

- By managing the material side of the product, a company can reduce its pollution effects, increase its eco-efficiency, or optimize its resource characteristics, to make a product easier to recycle, reuse, and decompose (Klewitz \& Hansen, 2014).

- Reducing a company's carbon footprint through supply chain improvements or switching to less energy or resource intensive products and services that deliver equivalent value can generate signi cant savings (Seebode et al., 2012).

- Becoming environmentally friendly tends to lower costs because companies end up reducing the inputs they use. In addition, the process generates added revenues from better products, improves operational efficiency, or enables companies to create new businesses (Nidumolu et al., 2009; Amini \& Bienstock, 2014).

- Improving operational efficiency, along with other sustainability initiatives, can give rise to innovations that inspire new business opportunities (Amini \& Bienstock, 2014).

\section{Analytical Methods using Web Search Techniques and Online Information}

Several examples of methods and techniques have been used to analyze and interpret online information in a way that could support decision making about the content of online marketing communications. Examples of such applications include: using news articles or social media, forums and blogs to predict market trends (Nassirtoussi et al., 2014), extracting business intelligence factors (Chung, 2014), predicting stock price movements (Schumaker et al., 2012) and foreign exchange markets (Nassirtoussi et al., 2015), using online user reviews to improve the helpfulness of voting mechanisms of online review systems (Cao et al., 2011), engaging online consumer comments to improve the service level and rating of online merchants (Qu et al., 2008), and using online consumer reviews to evaluate readership and helpfulness (Salehan \& Kim, 2016).

\section{Research Method}

\section{Research Approach}

We based the research approach on using existing sustainable business models and innovation frameworks in order to develop a set of keywords related to the sustainability aspects companies usually deal with. We then used a web search and text analytics tools to measure the frequency of use (web counts) of these sets of keywords on the websites of a sample of firms (di Tollo et al., 2015).

The research sample includes 387 product-driven firms from various sectors, such as: household goods and home construction, industrial engineering, oil equipment, services and distribution, industrial metals and mining, food production, automobiles and automotive parts, pharmaceuticals and biotechnology, and electronic and electrical equipment. The firms were selected from a list of the top $1000 \mathrm{EU} R \& D$ spenders for 2013 (provided by the EU Industrial R\&D Investment Scoreboard, http://iri.jrc.ec.europa.eu/scoreboard.html) by choosing the firms that have a product-dedicated webpage. Purely service companies were not included in the sample. The focus on firms with a higher degree of R\&D spending was used as an indicator for firms' orientation towards innovativeness and growth.

The dataset includes company data for R\&D spending, $R \& D$ growth for 2012 and for the previous 3 years, sales, sales growth for 2012 and for the previous 3 years, $R \& D$ intensity (R\&D spending vs sales), profit, profit growth for 2012 and for previous 3 years, profitability (income vs sales), number of employees, employee growth for 2012 and for the previous 3 years, capital expenditures (Capex), Capex growth for 2012 and for the previous 3 years. The nature of the data allows for quantitative examination of the relationship between online articulation of sustainability aspects and more typical performance metrics such as sales and $R \& D$ spending.

\section{Research Steps}

The key steps in the research process are summarized as follows. The research started with a detailed study of the literature on sustainability to identify frameworks describing its core components, aspects, or activities. The search for relevant articles used the Web of Science 


\section{Sustainability-related Communication Patterns on the Websites of European Top R\&D Spenders Giacomo Liotta, Stoyan Tanev, Andrea Gorra \& Alicja Izabela Pospieszala}

research database, focusing on the fields of environmental engineering, business and management, and searching for the keywords "sustainability" and "sustainable" in the titles of articles published before Dec. 31, 2014.

An additional search for the terms "innovation", "framework", and "model" within the corpus identified 9 relevant articles, including frameworks or models focusing on corporate sustainability (Amini \& Bienstock, 2014), business models (Boons \& Lüdeke-Freund, 2013; Bocken et al., 2014), sustainable innovation (Nidumolu et al., 2009; Haanaes et al., 2011; Seebode et al., 2012; Klewitz \& Hansen, 2014;), sustainable value-creation strategies (Lampikoski et al., 2014), and sustainable supply chain networks (van Bommel, 2011).

The sustainability frameworks described in the selected 9 articles were used to develop a set of 46 composite keywords related to different sustainability and sustainable innovation aspects. The data was collected by searching for the keywords on the 387 company websites using a web search tool that measured the frequency (web count) of the keywords on each of the websites. The keyword frequencies on a website were normalized by the number of sub-pages under the main company url. This was a way to account for the fact that larger companies tend to have a larger number of subpages and could be expected to have larger total keyword web counts (Libaers et al., 2010). The search process supplied a data matrix including the normalized frequencies of the keywords on each company's website (387 companies X 46 keywords).

A Principal Component Analysis (PCA) was applied to the above data matrix to identify four sustainability components or themes (independent groups of cooccurring keywords addressing different aspects of sustainability). The initial interpretation of the four components was based on the loading values of the specific keywords within a given PCA component. Four quantitative variables (corresponding to each PCA component) were constructed by adding all (normalized) keyword web counts corresponding to every PCA component weighted by the specific keyword loading. The firms were ranked in terms of a total sustainability communication metric -the sum of the four PCA variables. The most highly ranked firms were then characterized by the combinations of sustainability themes (sustainability communication patterns) discussed by them on their websites.

The last step in the process was to perform a correlation analysis of the four sustainability components, the R\&D spending, and sales of the firms, which provided an answer to the second research question.

\section{Summary of Results}

\subsection{Principal component analysis of the sustainability issues articulated online}

The application of the PCA lead to the identification (extraction) of four principal components that explained $72.31 \%$ of the total variance of the data we collected. The four components include 16 keywords out of the first set of 46 keywords. This is because some of the keywords had a relatively low representation on firms' websites or did not contribute significantly to the composition of the principal components (keywords with a loading value lower than 0.4 were removed from the analysis). The criterion to affirm the existence of a specific principal component was twofold: to have an eigenvalue higher or equal to 1 , as well as to have minimum 2 keywords (items) in the component with a loading value larger than 0.4 (Reinard, 2006).

Component 1 consists of seven keywords (Table 1). Except for "kw39", all of them are related to sustainable innovation focusing on organization, process, technology, and service. Interestingly, the keyword corresponding to product innovation (kw9) was not included in this component as its loading value was less than the 0.40 threshold. The sustainability aspect that has the lowest loading value refers to environmental policies, regulation, and legislation standards (kw39).

Component 2 includes six strong keywords with loading values higher than 0.6 (Table 2). Two of the keywords (kw37 and kw38) refer to customer benefits such as trust, loyalty, and satisfaction. Two other keywords (kw34, kw12) focus on financial, economic, and social benefits, and new customer market niches. In addition, Component 2 (kw35, kw16) includes a focus on asset optimization, better material and energy efficiencies, and improved resource utilization. Finally, kw38 refers to better customer relationships. All the above could be considered as benefits for customers, companies, or other key stakeholders.

Component 3 includes three keywords (Table 3) referring to several issues related to sustainable operations based on partnerships and cooperation: production, manufacturing, and technology development that aim at maximizing material, energy, and resource efficiencies. More specifically, kw14 (with the highest loading of 0.814 ) includes the terms 


\section{Sustainability-related Communication Patterns on the Websites of European Top R\&D Spenders Giacomo Liotta, Stoyan Tanev, Andrea Gorra \& Alicja Izabela Pospieszala}

Table 1. Keyword composition of Component 1

\begin{tabular}{|c|l|c|}
\hline Keyword & \multicolumn{1}{|c|}{ Component 1 composition } & Loading \\
\hline kw8 & $\begin{array}{l}\text { sustainable OR sustainability AND innovation OR innovativeness } \\
\text { AND organizational OR organisational OR corporate OR employee }\end{array}$ & 0.828 \\
\hline kw6 & $\begin{array}{l}\text { sustainable OR sustainability AND innovation OR innovativeness } \\
\text { AND technical OR technology OR technological }\end{array}$ & 0.815 \\
\hline kw11 & $\begin{array}{l}\text { sustainable OR sustainability AND innovation OR innovativeness OR } \\
\text { innovative OR new OR improve OR improvement OR improved AND } \\
\text { service }\end{array}$ & 0.744 \\
\hline kw7 & $\begin{array}{l}\text { sustainable OR sustainability AND innovation OR innovativeness } \\
\text { AND societal OR social OR ethic OR ethical OR responsible OR } \\
\text { responsibility OR equity OR CSR }\end{array}$ & 0.741 \\
\hline kw13 & $\begin{array}{l}\text { sustainable OR eco OR green OR environment OR environmental OR } \\
\text { ecological OR ecologic OR clean OR cleaner AND innovation OR } \\
\text { innovativeness }\end{array}$ & 0.728 \\
\hline kw10 & $\begin{array}{l}\text { sustainable OR sustainability AND innovation OR innovativeness OR } \\
\text { process }\end{array}$ & 0.662 \\
\hline kw39 & $\begin{array}{l}\text { sustainability OR sustainable OR environmental AND policy OR } \\
\text { regulation OR legislation OR engagement OR procedure OR } \\
\text { standard OR management system }\end{array}$ & 0.521 \\
\hline
\end{tabular}

'environmental', 'production' and 'manufacturing', while kw46 (second highest loading of 0.602) includes the terms 'sustainable', 'partnership', 'alliance', and 'cooperation'. Interestingly, kw16 (material, energy, and resource efficiencies) is cross-loaded with Component 2 , which focuses on benefits. Its presence in Component 3 could be considered as an expression of the focus of companies' sustainable operations.

Component 4 is composed of two keywords (Table 4), one of which has a much stronger loading -0.793 (kw40), as compared to 0.418 (kw7). The stronger keyword (kw40) emphasizes the challenges of meeting the requirements of environmental policies and regulations. The second keyword (kw7) expresses companies' commitment to societal, ethical, and responsible innovation. It is cross-loaded with Component 1, which focuses on sustainable innovation. Its presence in Component 4 could be considered as an expression of corporate innovation efforts that focus on meeting environmental policies and regulations.

\subsection{Interpretation of the principal components}

The keyword composition of the four PCA components supplies a basis for their interpretation as specific sustainability aspects, issues, or priorities. The interpretation should be based on keywords with the highest loading values (Reinard, 2006). The PCA analysis allowed us to construct four quantitative variables: $\mathrm{C} 1$, C2, C3 and C4. These correspond to each of the four principal components by adding the normalized web counts of each keyword included in a component, weighted by specific keyword loading. We can also define a total sustainability metric as follows: $\mathrm{C}_{-} \mathrm{T}=\mathrm{C} 1+$ $\mathrm{C} 2+\mathrm{C} 3+\mathrm{C} 4$. The total sustainability metric $\left(\mathrm{C}_{-} \mathrm{T}\right)$ offers the possibility of ranking the firms in terms of the degree of their online articulation of sustainability aspects corresponding to all four components. A search on the websites of companies selected from the most highly ranked firms was used to supply additional insights that could be applied in interpreting the four components, which is done in the next sections.

\subsubsection{Interpretation of Component 1: Sustainable innovation}

The keyword composition of Component 1 (Table 1) refers to sustainable innovation focusing on organization, process, technology, and services. Our textual examination of the websites of highly ranked firms suggested that Component 1 can be labelled 'Sustainable innovation' and interpreted as: Sustainability aspects related to innovative design, 


\section{Sustainability-related Communication Patterns on the Websites of European Top R\&D Spenders Giacomo Liotta, Stoyan Tanev, Andrea Gorra \& Alicja Izabela Pospieszala}

Table 2. Keyword composition of Component 2

\begin{tabular}{|c|c|c|}
\hline Keyword & Component 2 composition & Loading \\
\hline kw37 & $\begin{array}{l}\text { sustainability OR sustainable AND improve AND customer AND trust } \\
\text { OR loyalty OR fidelity OR allegiance OR satisfaction OR contentment }\end{array}$ & 0.807 \\
\hline kw35 & sustainability OR sustainable AND minimize OR optimize OR assets & 0.785 \\
\hline kw34 & $\begin{array}{l}\text { sustainability OR sustainable AND raise OR enhance AND finance OR } \\
\text { economic OR environmental OR social AND benefits OR return OR } \\
\text { revenue }\end{array}$ & 0.785 \\
\hline kw12 & $\begin{array}{l}\text { sustainable OR sustainability AND innovation OR innovativeness OR } \\
\text { new OR improve OR improvement OR improved AND larger AND } \\
\text { market OR niche OR customer }\end{array}$ & 0.721 \\
\hline kw38 & $\begin{array}{l}\text { sustainability OR sustainable AND lengthen OR sustain OR } \\
\text { strengthen OR improve OR enhance AND customer AND } \\
\text { relationships OR interaction OR communication }\end{array}$ & 0.678 \\
\hline kw16 & $\begin{array}{l}\text { maximize OR maximize OR increase OR improve AND efficiency OR } \\
\text { use OR effectiveness OR effectivity AND material OR energy OR } \\
\text { resource }\end{array}$ & 0.636 \\
\hline
\end{tabular}

organizational, technological, service, process and social innovation enabled by cooperation with external partners and informed by existing environmental policies, regulations, standards and management systems. (This and the three italicized sentences in the following paragraphs mark our key findings from this research.)

What is notable in the interpretation of Component 1 is its broad perspective on the relationship between sustainability and innovation, which goes beyond the typical concerns related to sustainable product design and innovation.

\subsubsection{Interpretation of Component 2: Stakeholder benefits} The keyword composition of Component 2 (Table 2) refers to sustainability-related benefits for customers, companies, or other key stakeholders. The textual examination of the websites of highly ranked firms suggests that Component 2 could be labelled 'Stakeholder benefits' and interpreted as: Sustainabilityrelated stakeholder benefits including a balance between sustainable business risks and rewards, and alignment with government policy, legislation and industrial practice.

\subsubsection{Interpretation of Component 3: Sustainable operations}

The keyword composition of Component 3 (Table 3) refers to sustainable operations enabled by valuable partnerships and cooperation. The textual examination of the websites of highly ranked firms suggests that
Component 3 could be labelled 'Sustainable operations' and interpreted as: Sustainable operations enabled by valuable partnerships and cooperation with suppliers and contractors focusing on delivering sustainable production solutions, implementing sustainable environmental policies, driving efficiency in resource use and implementing waste reduction systems.

It is worth noting that the cross loading of kw16 (material, energy, and resource efficiency) with Component 2 (Stakeholder benefits) suggests that companies' online communications discuss stakeholder benefits that are rooted in and emerge from their sustainable operations.

\subsubsection{Interpretation of Component 4: Dealing with environmental policy and regulation challenges}

The keyword composition of Component 4 (Table 4) refers to the challenges of meeting the requirements of environmental policies and regulations, along with companies' commitment to societal, ethical, and responsible innovation. Textual examination of the websites of highly ranked firms suggested that Component 4 can labelled 'Dealing with environmental policy and regulation challenges' and interpreted as: Dealing with the challenges of meeting the requirements of environmental policies and regulations by adopting governance principles driven by social responsibility and environmental concerns.

Interestingly, kw7 (ethical or responsible innovation) of Component 4 appears also in Component 1 (Sustainable 


\section{Sustainability-related Communication Patterns on the Websites of European Top R\&D Spenders Giacomo Liotta, Stoyan Tanev, Andrea Gorra \& Alicja Izabela Pospieszala}

Table 3. Keyword composition of Component 3

\begin{tabular}{|c|l|c|c|}
\hline Keyword & \multicolumn{1}{|c|}{ Component 3 composition } & \multicolumn{1}{|c|}{$\begin{array}{r}\text { Comp. } \\
\text { Loading 2 cross } \\
\text { loading }\end{array}$} \\
\hline kw14 & $\begin{array}{l}\text { sustainable OR eco OR green OR environment OR } \\
\text { environmental OR ecological OR ecologic OR clean OR } \\
\text { cleaner AND production OR manufacturing OR manufacture } \\
\text { OR development OR technology }\end{array}$ & 0.814 & 0.602 \\
\hline kw46 & $\begin{array}{l}\text { sustainability OR sustainable OR eco OR green OR } \\
\text { environmental OR ecological OR ecologic OR clean AND } \\
\text { partner OR partnership OR cooperation OR collaboration OR } \\
\text { collaborative OR cooperative OR alliance } \\
\text { maximize OR maximize OR increase OR improve AND } \\
\text { efficiency OR use OR effectiveness OR effectivity AND } \\
\text { material OR energy OR resource }\end{array}$ & 0.543 \\
\hline kw16 & 0.636 \\
\hline
\end{tabular}

innovation) with a higher loading value $(0.741$ as compared to 0.418 in Component 4). Such a link between Components 1 and 4 suggests that some of the key aspects of companies' sustainable innovation efforts are driven by the need to address the requirements of environmental policies and regulations.

\subsection{Examining firms' online communication patterns of sustainability aspects}

Our analysis of the emerging combinations of sustainability aspects that are most frequently articulated by firms on their websites provided insights about their most typical online communication patterns. The emerging combinations of sustainability components we analyzed will need a criterion to identify a minimum threshold level of online articulation below which a specific component will be considered as negligible. To do that, we normalized each component variable by its maximum value, for example $\mathrm{Cl}^{\prime}=$ $\mathrm{C} 1 / \max (\mathrm{C} 1)$. Thus, the maximum value of the four normalized variables is 1 and their minimum value is zero. After several trials, a threshold value of 0.2 was chosen since it allowed us to identify a suitable subset of firms that manifest distinguishable communication patterns. In this way, the four component variables of each of the 387 firms was transformed into a binary form, as "zeros" (for the companies that have a component value below 0.2) and "ones" (for the companies that have a component value above 0.2 ).

We used an intuitive labelling scheme for the online communication patterns comprised of "zeros" and "ones". For example, a 1110 pattern corresponds to companies with $\mathrm{C} 1, \mathrm{C} 2$, and C3 values higher than 0.2 (hence, the first three "ones" in the label), and a C4 value lower than 0.2 (hence, the last "zero" in the label). Table 5 shows the most dominant communication patterns. Interestingly, the 0000 pattern corresponds to $54 \%$ of the companies. This means that the choice of a 0.2 threshold allowed us to identify almost $50 \%$ of the firms as not very active in articulating their sustainability concerns online. Reducing the threshold value would have decreased the number of " 0000 " firms, but would still have left many of them as non-active. We thus believe,

Table 4. Keyword composition of Component 4

\begin{tabular}{|c|c|c|c|}
\hline Keyword & Component 4 composition & Loading & $\begin{array}{l}\text { Comp. } 1 \\
\text { cross } \\
\text { loading }\end{array}$ \\
\hline kw40 & $\begin{array}{l}\text { sustainability OR sustainable OR environmental AND policy } \\
\text { OR regulation OR legislation issue OR problem OR challenge }\end{array}$ & 0.793 & \\
\hline kw7 & $\begin{array}{l}\text { sustainable OR sustainability innovation OR innovativeness } \\
\text { AND societal OR social OR ethic OR ethical OR responsible } \\
\text { OR responsibility OR equity OR CSR }\end{array}$ & 0.418 & 0.741 \\
\hline
\end{tabular}




\section{Sustainability-related Communication Patterns on the Websites of European Top R\&D Spenders Giacomo Liotta, Stoyan Tanev, Andrea Gorra \& Alicja Izabela Pospieszala}

by working with the study's parameters, that the 0.2 value was a suitable choice since it both demonstrated the methodology used in the search and also allowed us to examine firms' dominant communication patterns.

Five communication patterns were used by at least $3.0 \%$ of companies: 0010, 0110, 1010, 1110, and 1111 (see Table 11). The companies that intensively communicated issues related to all four components accounted for only $3.62 \%$ ( 14 firms). The most dominant communication pattern $(20.16 \%, 78$ firms) included only Component 3 (0010) - Sustainable operations. The second dominant pattern was 0110 (8,01\%, 31 firms) Sustainable operations and Stakeholder benefits, followed by $1010 \quad(4,65 \%, 18$ firms $)$ - Sustainable operations and Stakeholder innovation. The 1110 communication pattern - Sustainable operations, Stakeholder benefits, and Sustainable Innovation, is manifested by $4.39 \%$ (17) of the firms.

\subsection{Correlation between sustainability and company performance metrics}

The present section describes the results gathered from a correlation analysis we did that focused on examining the relationships between sustainability components and two of a company's key performance indicators $\mathrm{R} \& \mathrm{D}$ spending and Sales (Table 6). The correlation coefficients, along with the rest of the performance metrics described in the Research method section, were found to be not statistically significant. We should emphasize the fact that the type of correlated variables used (online articulation of sustainability vs. performance metrics) was quite different. The variables $\mathrm{C} 1$ to $\mathrm{C} 4$ refer to the frequency of articulating online specific sustainability aspects, while the $R \& D$ and Sales variables were based on numerical data about annual R\&D company spending and sales, provided by the companies themselves. This is an important point since it suggests that the degree of correlation between the variables used should be interpreted in relative rather than absolute terms.

The total sustainability variable $\left(\mathrm{C}_{-} \mathrm{T}\right)$ manifests a high degree of correlation with Sales (0.445). We found that the distinction between high and medium degrees of correlation follows the classification suggested by Cohen (1988), where correlation coefficients larger than 0.371 refer to high correlation, and ones between 0.243 and 0.371 to medium correlation.

The highest correlation coefficient is between Component 1 (Sustainable innovation) and Sales (0.463). The second highest correlation coefficient $(0.416)$ is the one between Component 4 (Dealing with environmental policy and regulation challenges) and Sales. The other two sustainability components (C2 - Stakeholder

Table 5. Emerging combinations of sustainability components (online communication patterns). The light grey coloured rows highlight the most dominant patterns.

\begin{tabular}{|c|c|c|c|c|c|}
\hline \multicolumn{7}{|c|}{ Online communication patterns } \\
\hline Label & $\begin{array}{c}\text { C1 } \\
\text { Sustainable } \\
\text { innovation }\end{array}$ & $\begin{array}{c}\text { C2 } \\
\text { Stakeholder } \\
\text { benefits }\end{array}$ & $\begin{array}{c}\text { C3 } \\
\text { Sustainable } \\
\text { operations }\end{array}$ & $\begin{array}{c}\text { C4 Env. policy } \\
\text { \& regulation } \\
\text { challenges' }\end{array}$ & $\begin{array}{c}\text { Total \% } \\
\text { (\# firms) }\end{array}$ \\
\hline 0010 & 0 & 0 & 1 & 0 & $20.16 \%(78)$ \\
\hline 0110 & 0 & 1 & 1 & 0 & $8.01 \%(31)$ \\
\hline 1010 & 1 & 0 & 1 & 0 & $4.65 \%(18)$ \\
\hline 1110 & 1 & 1 & 1 & 0 & $4.39 \%(17)$ \\
\hline 1111 & 1 & 1 & 1 & 1 & $3.62 \%(14)$ \\
\hline 1011 & 1 & 0 & 1 & 1 & $2.58 \%(10)$ \\
\hline 0100 & 0 & 1 & 0 & 0 & $1.29 \%(5)$ \\
\hline 1000 & 1 & 0 & 0 & 0 & $1.03 \%(4)$ \\
\hline 0001 & 0 & 0 & 0 & 1 & $0.26 \%(1)$ \\
\hline 0000 & 0 & 0 & 0 & 0 & $54.01 \%(209)$ \\
\hline Total & $\mathbf{5}$ & $\mathbf{4}$ & $\mathbf{6}$ & $\mathbf{3}$ & $\mathbf{1 0 0 . 0 0 \%}$ \\
\hline
\end{tabular}




\section{Sustainability-related Communication Patterns on the Websites of European Top R\&D Spenders Giacomo Liotta, Stoyan Tanev, Andrea Gorra \& Alicja Izabela Pospieszala}

Table 6. Correlation between sustainability components and performance metrics

\begin{tabular}{|l|c|c|}
\hline & $\begin{array}{c}\text { Sales 2012 } \\
(\mathbf{€ M})\end{array}$ & R\&D 2012 (€M) \\
\hline C1: Sustainable innovation & 0.463 & 0.343 \\
\hline C2: Stakeholder benefits & 0.365 & 0.323 \\
\hline C3: Sustainable operations & 0.340 & 0.275 \\
\hline $\begin{array}{l}\text { C4: Dealing with environmental policy and } \\
\text { regulation challenges }\end{array}$ & 0.416 & 0.304 \\
\hline C_T: Total sustainability component & 0.445 & 0.352 \\
\hline
\end{tabular}

benefits, and C3 - Sustainable operations) manifest a medium correlation with Sales - 0.365 and 0.340, respectively. In addition, a medium degree of correlation (0.352) was found between the total sustainability component $\left(\mathrm{C}_{-} \mathrm{T}\right)$ and $\mathrm{R} \& \mathrm{D}$ spending. The correlation between sustainability and $R \& D$ spending was seen as being driven by Sustainable innovation (0.343) and Stakeholder benefits (0.323). The lowest correlation (0.275) was identifiable between Sustainable operations and $R \& D$ spending.

\section{Discussion of Results}

There are two main sets of results. The first set of results showed the online communication patterns represented by specific combinations of sustainability themes articulated by companies on their websites. These patterns gave us an answer to the first research question: How do companies articulate the sustainability aspects of their businesses on their websites? The dominant communication patterns we found were: 0010 (20.16\%), 0110 (8.01\%), 1010 (4.65\%), 1110 (4.39\%), and 1111 (3.62\%) (see first five rows in Table 11).

The most noticeable observation in these patterns is that Component 3 (Sustainable operations) appears in all of them. In addition, the most dominant pattern consists of Component 3 alone. This suggests that companies build their online communication of sustainability concerns around issues related to sustainable operations, partnerships and cooperation with suppliers and contractors. They focus on delivering sustainable production solutions, implementing sustainable environmental policies and effective environmental management systems, gaining efficiency in resource use, and constantly working on waste reduction systems (see section 4.2.3).

The second most dominant communication pattern is 0110 which corresponds to $8.01 \%$ of the firms and includes two themes: Sustainable operations and
Stakeholder benefits. This finding supports insights formulated by Sarkis, Gonzalez-Torre, and Adenso-Diaz (2010), who indicated a relationship between stakeholder concerns and firms' environmental practices. According to Peloza et al., (2012), many firms engage in sustainability initiatives with the expectation of financial returns based on valuable relationships with stakeholders. Firms that meet stakeholder expectations for corporate environmental performance "show less unsystematic risk, compared to firms with low environmental legitimacy" (Kumar \& Christodoulopoulou, 2014).

The other dominant communication patterns were 1010 (4.65\% of the firms focus on Sustainable operations and innovation), 1110 (4.39\% of the firms focus on the first three sustainability components), and 1111 (3.62\% of the firms focus on all four components). This finding shows a tendency for companies to claim innovativeness in the context of their sustainable operations and stakeholder relationships. What is interesting is that the fourth component (Innovation and Dealing with environmental policy and regulation challenges) appears only in the most dominant pattern when all of the other components are also included. The crossloading of one of its keywords (kw7) with Sustainable innovation suggests a strong link between regulations, policy, and innovation.

The second set of results answers the second research question: In what ways does the degree of articulating specific sustainability aspects relate to a company's performance metrics, such as sales and $R \& D$ expenditure? Our findings (see Table 6) show that the online communication about sustainability issues by companies has a high degree of correlation with sales and a medium (lower) degree of correlation with $R \& D$. We believe the higher correlation between communicating sustainability aspects and sales marks an interesting finding. It is inline with existing theoretical and empirical research on the relationship 


\section{Sustainability-related Communication Patterns on the Websites of European Top R\&D Spenders Giacomo Liotta, Stoyan Tanev, Andrea Gorra \& Alicja Izabela Pospieszala}

between sustainability, customer satisfaction, stronger stakeholder relationships, and superior financial performance (Peloza et al., 2012). In addition, according to Baron (2001), as well as McWilliams and Siegel (2001), firms predominantly tend to engage in sustainable profit maximizing practices.

These results suggest that customers should more closely examine a company's sustainability activities when making their purchase decisions. Our research joins others in indicating that customers will favour firms with good sustainability performance (Gong et al., 2019). Our results reveal that sustainability plays an important role in companies' sales arguments and communications to customers in new market niches (Klink et al., 2014). Companies tend to refer to good sustainability practices in marketing their customer value propositions by claiming the material, energy, and resource efficiency of their products as a distinct dimension of value (Patala et al., 2016).

We find it interesting that the highest correlation between sustainability and sales appears to be driven by: a) Sustainable innovation, and b) Dealing with the challenges of environmental policy and regulations. We find the considerable impact of companies making sustainable innovation claims in their online communications as understandable, since a firm's innovativeness is an important factor in developing its corporate public image.

The lower degree of correlation between the total sustainability variable and $R \& D$ spending can be explained by the less frequent references to $R \& D$ activities on company websites, in large part due to their longer-term potential impact on business operations. On the other hand, the link between R\&D spending and Sustainable innovation seems to make sense to us, since R\&D activities have a direct impact on companies' innovation outcomes.

\section{Conclusion}

Our study makes two main contributions. The first contribution is methodological. We adopted a webbased data collection methodology, which was based on publicly available textual data, and used textual analytics tools to examine the online communication patterns of sustainability issues by top EU R\&D spenders, focusing on the relationship between degree of articulating specific sustainability issues, corporate sales, and R\&D spending. The method used can easily be replicated through adopting open source web search and text analytics resources that can be used by data analysts.

The second contribution is theoretical. The results offer what we believe to be valuable insights about the communication patterns top EU R\&D spenders use to articulate the sustainability aspects of their businesses, providing a basis for comparison with other organizations. The focus on sustainable operations serves as most companies' key communication pillar, which they complement with a focus on stakeholder benefits and sustainable innovation. One of the most interesting findings suggests a strong relationship between communicating sustainable innovation aspects and sales, which is a promising message to companies looking for evidence about the potential positive impact of their commitment to sustainable operations and innovation on their market position. We believe that the results will be of interest to both researchers, company decision makers, and marketing communication experts who can both learn from and replicate the method used here in similar other contexts.

\section{Acknowledgement}

Our colleague and friend Dr. Giacomo Liotta, Associate Professor at Aalborg University in Copenhagen, passed away in December 2016, a few months after being diagnosed with cancer. It is our pleasure to acknowledge Giacomo's inspiration and contribution to this study. His academic dedication and professionalism have been a great example for us. 


\section{Sustainability-related Communication Patterns on the Websites of European Top R\&D Spenders Giacomo Liotta, Stoyan Tanev, Andrea Gorra \& Alicja Izabela Pospieszala}

\section{References}

Amfori. 2019. A Guide to Effective Sustainability Communications.

https://www.amfori.org/sites/default/files/amfori_eff ective_sustainability_communication_guide_2019_0_ 1.pdf

Amini, M. \& Bienstock, C. (2014). Corporate Sustainability: an integrative definition and framework to evaluate corporate practice and guide academic research. Journal of Cleaner Production, 76: 12-19.

https://doi.org/10.1016/j.jclepro.2014.02.016

Baron, D. 2001. Private politics, corporate social responsibility and integrated strategy. Journal of Economics and Management Strategy, 10: 7-45. https://doi.org/10.1111/j.1430-9134.2001.00007.x

Bocken, N.M.P., Short, S.W., Rana, P., \& Evans, S. 2014. A literature and practice review to develop sustainable business model archetypes. Journal of Cleaner Production, 65: 42-56.

https://doi.org/10.1016/j.jclepro.2013.11.039

Bommel, H.W.M. Van. 2011. A conceptual framework for analyzing sustainability strategies in industrial supply networks from an innovation perspective. Journal of Cleaner Production, 19(8): 895-904.

https://doi.org/10.1016/j.jclepro.2010.12.015

Boons, F., Montalvo, C., Quist, J., \& Wagner, M. 2013. Sustainable innovation, business models and economic performance: an overview. Journal of Cleaner Production, 45: 1-8.

https://doi.org/10.1016/j.jclepro.2012.08.013

Boons, F., \& Lüdeke-Freund, F. 2013. Business models for sustainable innovation: State-of-the-art and steps towards a research agenda. Journal of Cleaner Production, 45: 9-19.

DOI: $10.1016 /$ j.jclepro.2012.07.007

Cao, Q., Duan, W., \& Gan, Q. 2011. Exploring determinants of voting for the "helpfulness" of online user reviews: A text mining approach. Decision Support Systems, 50: 511-521.

https://doi.org/10.1016/j.dss.2010.11.009

Carrillo-Hermosilla, J., del Río, P., \& Könnölä, T. 2010. Diversity of eco-innovations: reflections from selected case studies. Journal of Cleaner Production, 18: 10731083.

DOI: 10.1016/j.jclepro.2010.02.014

Charter, M., \& Clark, T. 2007. Sustainable Innovation Key conclusions from Sustainable Innovation Conferences 2003-2006 organised by The Centre for Sustainable Design. Centre for Sustainable Design, University for the Creative Arts. Last retrieved on Nov. 4, 2019, from:

http://cfsd.org.uk/Sustainable\%20Innovation/Sustain able_Innovation_report.pdf

Chung, W. 2014. BizPro: Extracting and categorizing business intelligence factors from textual news articles. International Journal of Information
Management, 34: 272-284.

https:1/doi.org/10.1016/j.ijinfomgt.2014.01.001

Claudy, M., Peterson, M., and Pagell, M. 2016. The Roles of Sustainability Orientation and Market Knowledge Competence in New Product Development Success. Journal of Product Innovation Management, 33(S1): 72-85.

https://doi.org/10.1111/jpim.12343

Cohen, J. 1988. Statistical Power Analysis for the Behavioural Science. 2nd ed. Hillsdale: Lawrence Erlbaum Associates.

di Tollo, G., Tanev, S., Liotta, G., \& De March, D. 2015. Using online textual data, principal component analysis and artificial neural networks to study business and innovation practices in technologydriven firms. Computers in Industry, 74: 16-28.

https://doi.org/10.1016/j.compind.2015.08.006

Fernández, Y.F., Fernández López, M.A., and Olmedillas Blanco, B. 2018. Innovation for sustainability: The impact of R\&D spending on CO2 emissions. Journal of Cleaner Production, 172: 3459-3467.

https://doi.org/10.1016/j.jclepro.2017.11.001

Gong, M., Gao, Y., Koh, S.C., Sutcliffe, C.M., \& Cullen, J. 2019. The Role of Customer Awareness in Promoting Firm Sustainability and Sustainable Supply Chain Management. International Journal of Production Economics (July 2017).

https://doi.org/10.2139/ssrn.3328061

Haanaes, K., Balagopal, B., Arthur, D., King, M., Velken, I., Kruschwitz, N., \& Hopkins, M. 2011. First Look: The Second Annual Sustainability \& Innovation Survey. MIT Sloan Management Review, 52(2): 77-83.

Hansen, E., Grosse-Dunker, R. \& Reichwald, R. 2009. Sustainability Innovation Cube - A Framework to Evaluate Sustainability-Oriented Innovations. International Journal of Innovation Management, 13(4): 683-713.

https://doi.org/10.1142/S1363919609002479

Klewitz, J. \& Hansen, E.G. 2014. Sustainability-oriented innovation of SMEs: a systematic review. Journal of Cleaner Production, (65): 54-75.

https://doi.org/10.1016/j.jclepro.2013.07.017

Klink, J., Langen, N., Hecht, S., \& Hartmann, M. 2014. Sustainability as Sales Argument in the Fruit Juice Industry? An Analysis of On-Product Communication. International Journal on Food System Dynamics, International Center for Management, Communication, and Research, Vol. 5(3): 1-15.

DOI: 10.18461/ijfsd.v5i3.534

Kumar, V., \& Christodoulopoulou, A. 2014. Sustainability and branding: An integrated perspective. Industrial Marketing Management, 43(1): 6-15.

https://doi.org/10.1016/j.indmarman.2013.06.008

Lampikoski, T., Westerlund, M., Rajala, R., \& Möller, K. 2014. Green innovation games: Value-creation strategies for corporate sustainability. California Management Review, 57(1): 88-115.

https://doi.org/10.1525/cmr.2014.57.1.88 


\section{Sustainability-related Communication Patterns on the Websites of European Top R\&D Spenders Giacomo Liotta, Stoyan Tanev, Andrea Gorra \& Alicja Izabela Pospieszala}

Libaers, D., Hicks, D., Porter, A. 2010. A taxonomy of small firm technology commercialization. Ind. Corp. Change, 6: 1-35. https://doi.org/10.1093/icc/dtq039

Matos, S., \& Silvestre, B. 2013. Managing stakeholder relations when developing sustainable business models: the case of the Brazilian energy sector. Journal of Cleaner Production, 45: 61-73. https://doi.org/10.1016/j.jclepro.2012.04.023

McWilliams \& Siegel 2001. Corporate Social Responsibility: a Theory of the Firm Perspective. The Academy of Management Review, Vol. 26, No. 4 (Oct., 2001): 504-505.

Nassirtoussi, A., Aghabozorgi, S., Wah, T., \& Ngo, D. 2015. Text mining of news-headlines for FOREX market prediction: A Multi-layer Dimension Reduction Algorithm with semantics and sentiment. Expert Systems with Applications, 42: 306-324. https://doi.org/10.1016/j.eswa.2014.08.004

Neutzling, D.M., Land, A., Seuring, S., \& Nascimento, L.F.M. do. 2018. Linking sustainability-oriented innovation to supply chain relationship integration. Journal of Cleaner Production, 172: 3448-3458. https://doi.org/10.1016/j.jclepro.2017.11.091

Nidumolu, R., Prahalad, C.K., \& Rangaswami, M. 2009. Why sustainability is now the key driver of innovation. Harvard Business Review, 87(9): 56-64.

Patala, S., Jalkala, A., Keränen, J., Väisänen, S., Tuominen, V., \& Soukka, R. 2016. Sustainable value propositions: Framework and implications for technology suppliers. Industrial Marketing Management, 59: 144-156.

https://doi.org/10.1016/j.indmarman.2016.03.001

Peloza, J., Loock, M., Cerruti, J., \& Muyot, M. 2012. Sustainability: How Stakeholder Perceptions Differ from Corporate Reality. California Management Review, 55(1): 74-97. https://doi.org/10.1525/cmr.2012.55.1.74

Qu, Z., Zhang, H., \& Li, H. 2008. Determinants of online merchant rating: Content analysis of consumer comments about Yahoo merchants. Decision Support Systems, 46: 440-449.

https://doi.org/10.1016/j.dss.2008.08.004

Reinard, J. 2006. Communications Research Statistics. Sage Publications, Thousand Oaks.

Salehan, M., \& Kim, D. 2016. Predicting the performance of online consumer reviews: A sentiment mining approach to big data analytics. Decision Support Systems, 81: 30-40.

https://doi.org/10.1016/j.dss.2015.10.006

Schumaker, R., Zhang, Y., Huang, C.-N., \& Chen, H. 2012. Evaluating sentiment in financial news articles. Decision Support Systems, 53: 458-464. https://doi.org/10.1016/j.dss.2012.03.001 